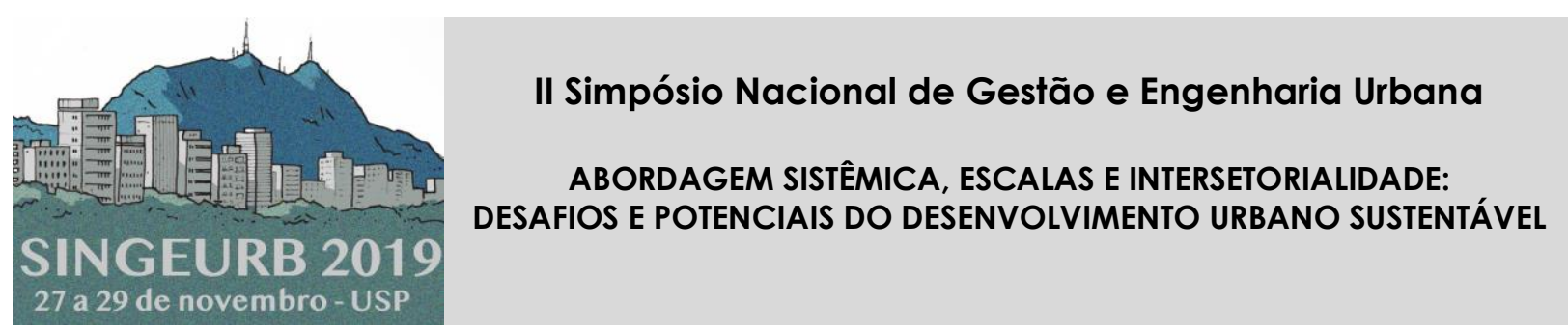

\title{
Jardins Verticais e Arborização Tradicional: uma comparação dos serviços ambientais e custos ${ }^{1}$
}

\section{Green Walls and Traditional Arborization Programs: a comparison of environmental and budget services}

\author{
Viadana, Tazio'; Abiko, Alex² \\ ' Escola Politécnica - Universidade de São Paulo, Brasil, tazio.viadana@usp.br \\ 2 Escola Politécnica - Universidade de São Paulo, alex.abiko@usp.br
}

\begin{abstract}
RESUMO
O adensamento das áreas urbanas, proporcionou a precarização dos índices de qualidade e conforto ambientais e o aumento da polvição visual. Como alternativa para melhorar o conforto ambiental dos residentes das áreas urbanas a utilização de jardins verticais tem se tornado um recurso amplamente utilizado, principalmente nas áreas centrais. No entanto, no caso da cidade São Paulo, os jardins verticais passaram a ser incluídos em Termos de Ajustamento de Conduta (TAC) como meios de compensação ambiental. Este artigo pretende comparar os custos e o fornecimento de serviços ambientais como: absorção de gás carbônico, liberação de vapor d'água e diversidade biológica de jardins verticais com plantio de árvores utilizadas em programas de arborização urbana, e tradicionais como meios de compensação ambiental.
\end{abstract}

Palavras-chave: Jardim Vertical, Árvore, Comparação.

\begin{abstract}
The densification of urban areas has led to the precariousness of the indices of environmental quality and comfort and the increase of visual pollution. As an alternative to improving the environmental comfort of residents of urban areas the use of green walls has become a widely used resource, especially in the central areas. However, in the case of the city of São Paulo, green walls are now included in the TAC as environmental compensation. This article aims to compare the costs and supply of environmental services such as: carbon absorption, water vapor release and biological diversity of vertical gardens with tree planting used in urban afforestation programs, and traditional as means of environmental compensation.
\end{abstract}

Keywords: Green Walls, Trees, Comparison.

\section{INTRODUÇÃO}

O surgimento dos grandes centros urbanos demandou o desenvolvimento de novas áreas verdes que não interferissem nas dinâmicas do mercado imobiliário. Desse modo, surgiram os jardins verticais. O principal idealizador dos jardins verticais é o botânico e designer francês Patrick Blanc, o qual realiza esse trabalho desde 1988. O projeto de envelopamento das

1 VIADANA, Tazio; ABIKO, Alex. Jardins verticais e arborização tradicional: uma comparação dos serviços ambientais e custos. In: II SIMPÓSIO NACIONAL DE GESTÃO E ENGENHARIA URBANA: SINGEURB, 2019, São Paulo. Anais... Porto Alegre: ANTAC, 2019. 
fachadas visa restaurar a qualidade ambiental de áreas densamente urbanizadas, inserindo a natureza à cidade. (PERINI et al., 2013)

Segundo Köhler (2008) os principais benefícios associados a essa estrutura envolvem as práticas ambientais, economia de espaço, redução significativa da temperatura, captura de dióxido de carbono, melhoria da qualidade do ar, das condições de conforto ao ar livre e aumento da biodiversidade selvagem urbana. A efetividade destes benefícios é obtida de acordo com o tamanho específico para cada jardim vertical.

Segundo Manso e Castro-Gomes (2015), os jardins verticais referem-se a qualquer sistema que permite o desenvolvimento de vegetais em superfícies verticais. Os jardins verticais podem ser subdivididos em dois sistemas principais, as fachadas verdes e as paredes vivas. A distinção entre os sistemas é evidente, enquanto as fachadas verdes os vegetais, geralmente espécies trepadeiras, crescem ao longo das paredes, o recente conceito das paredes vivas consiste em painéis ou módulos de diferentes materiais compostos de 3 camadas: estrutura metálica do suporte, placa de PVC e duas mantas de feltro ou geotêxtil, além de sistemas de irrigação e nutrição embutidos no sistema para suportar uma variedade de espécies vegetais, para que proporcione um ambiente adequado havendo um crescimento uniforme ao longo da superfície.

De acordo com Blanc (2008), em ambas as tipologias é necessário realizar um estudo prévio sobre as plantas que serão utilizadas, considerando suas exigências hídricas, nutrição e irradiação solar. Devido à ação dos ventos e da irradiação solar, intensificados pela altura em que os painéis são instalados, é indispensável um sistema de irrigação automático por gotejamento ou sprays para fornecer a umidade adequada ao desenvolvimento dos vegetais. Porém, o excesso de água impede a respiração radicular e consequentemente a absorção de nutrientes, comprometendo as espécies do jardim vertical. A vegetação utilizada é diversificada, prioriza espécies nativas, como as rasteiras, arbustos ou trepadeiras. Com relação à questão nutricional, no caso de trepadeiras plantadas no solo ou em paredes vivas de vaso, é realizada a adubação granular. Em paredes vivas é realizada a hidroponia, técnica de adubação na qual uma solução contendo os nutrientes é diluída na água de irrigação. (IRWIN, 2016)

O uso crescente da implantação dos jardins verticais nos projetos de paisagismo na cidade de São Paulo é decorrente do Decreto 55.994 de março de 2015, o qual admite a conversão da compensação em obras e serviços em jardins verticais e coberturas verdes. (SÃO PAULO, 2015)

\section{OBJETIVO}

Verificar a viabilidade de jardins verticais na utilização em Termos de Ajustamento de Conduta (TAC), instrumento de tratamento de conflitos os quais têm como objeto a adequação da conduta de um violador às exigências legais.

Esta viabilidade será analisada comparando os serviços ecossistêmicos prestados por jardins verticais e por espécies arbóreas, usualmente utilizadas nos programas de arborização urbana, além de uma comparação entre os custos de instalação, plantio e manutenção dos jardins verticais e de espécies arbóreas.

\section{METODOLOGIA}

Um projeto sustentável necessita que os impactos ao meio ambiente sejam mitigados, os ganhos socioambientais sejam relevantes e seu orçamento seja compatível com os recursos disponíveis para sua instalação e manutenção.

Segundo Cameron et at. (2014), para determinar a sustentabilidade do jardim vertical, parâmetros de acúmulo de carbono na massa vegetal e os serviços ambientais, tais como: diminuição da temperatura, aumento da umidade do ar, redução do material particulado atmosférico, aumento da biodiversidade urbana são comparados com os mesmos parâmetros para uma árvore adulta. 
O tipo de jardim vertical a ser usado como modelo de comparação será a parede viva ou "Living Wall System", modelo mais utilizado pelo município de São Paulo em áreas desprovidas de vegetação, tais como, as vias de trânsito intenso com elevada taxa de impermeabilização do solo, dificultando o plantio de árvores no local.

A árvore modelo utilizada para a comparação será a Tipuana tipu, com expectativa de vida de 60 anos. Possui uma copa ampla e densa, podendo atingir até 15 metros de altura, pesar até 20 toneladas, possuir uma copa larga com uma área aproximada de $36 \mathrm{~m}^{2}$ ((HALLÉ et at., 1978). Esta espécie foi amplamente utilizada em programas de arborização urbana no passado, pois seu crescimento rápido e de grande porte a torna ideal para o plantio em canteiros centrais, parques, praças com ressalvas para o plantio em calçadas, devido a agressividade de suas raízes. (MARTINS e LUZ, 2013)

\section{RESULTADOS E DISCUSSÕES}

Para o parâmetro de sequestro de $\mathrm{CO}_{2}$ das árvores tem-se como principal estrutura de armazenamento de $\mathrm{CO}_{2}$ o tronco, por apresentar maior biomassa. Considerando que o teor de umidade do tronco seja 16,30\%, temos aproximadamente 11 t da biomassa localizada no tronco seco. As folhas representam cerca de $5 \%(0,84 t)$, e as raízes 30\%, $(5,00 t)$ (BUCKRIDGE, 2018). A lignina, um dos principais constituintes das plantas está associada à celulose. Com base na sua estrutura, $\mathrm{C}_{9} \mathrm{H}_{10} \mathrm{O}_{2}, 72 \%$ da sua massa molecular corresponde ao carbono, portanto, no tronco seco da tipuana considerada teremos $8 t$ de carbono. Para uma estimativa de vida de 60 anos, serão absorvidas aproximadamente $130 \mathrm{kgCO}_{2} / \mathrm{ano}$. Segundo dados da Secretaria Municipal de Urbanismo e Licenciamento e GeoSampa, a cidade possui cerca de 652.400 árvores nas vias públicas totalizando o armazenamento de 85.000 †CO 2 /ano.

Segundo Blanc (2008), em paredes vivas são utilizadas espécies de pequeno porte, como: barba de serpente (Ophiopogon jaburan), colar de pérolas (Senecio rowleyanus), flor canhota (Scaevola aemula), jiboia (Epipremmum pinnatum), samambaia (Nephorolepis exaltata), aspargo (Asparagus densiflorus), véu de noiva (Gibasis pelucida), não se recomendando o cultivo de plantas que possuam folhas delicadas, com raízes agressivas, longas e pesadas.

As espécies de pequeno porte são compostas em sua maioria por folhas, estruturas com maior concentração de água, e não possuem tronco lenhoso tendo baixo acúmulo de carbono na sua biomassa. Assim, estima-se para uma parede viva a absorção de $33 \mathrm{kgCO}_{2} /$ ano para uma área de $36 \mathrm{~m}^{2}$, equivalente à projeção da copa da tipuana no solo, conforme gráfico 1. (PULSELLI et al, 2014)

Gráfico 1 - Incorporação de carbono na biomassa - kgCO²/ano

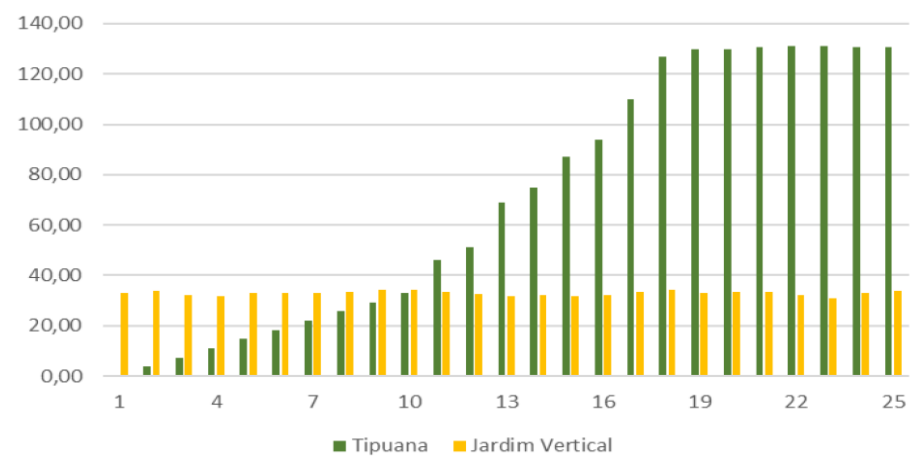

Fonte: Os autores, 2018

Quanto à questão hídrica, uma tipuana adulta consome 720L de água por dia e libera até $400 \mathrm{~L}$ de água, totalizando $146 \mathrm{~m}^{3} / \mathrm{ano}$. Extrapolando para as 652.400 árvores teremos $95.250 \mathrm{~m}^{3}$ de vapor d'água por ano. Essa taxa de evapotranspiração cria um bombeamento hídrico 
aumentando a umidade do ar, tornando-o fresco e menos polvído, removendo o material particulado presente no ar urbano. (KLINE et al. 1970)

As espécies utilizadas nas paredes vivas necessitam de grande quantidade de água contínua para seu desenvolvimento. Por não ter contato direto com o solo é necessária a instalação de um sistema irrigação automático que permita a manutenção da umidade no substrato. Assim, uma parede viva de $36 \mathrm{~m}^{2}$ demanda $57,60 \mathrm{~L} /$ dia totalizando $21 \mathrm{~m}^{3} /$ ano o que corresponde a uma taxa de evapotranspiração de $71 \mathrm{~m}^{3} /$ ano, segundo o gráfico 2.

Gráfico 2 - Liberação de vapor d'água por evapotranspiração - m³/ano

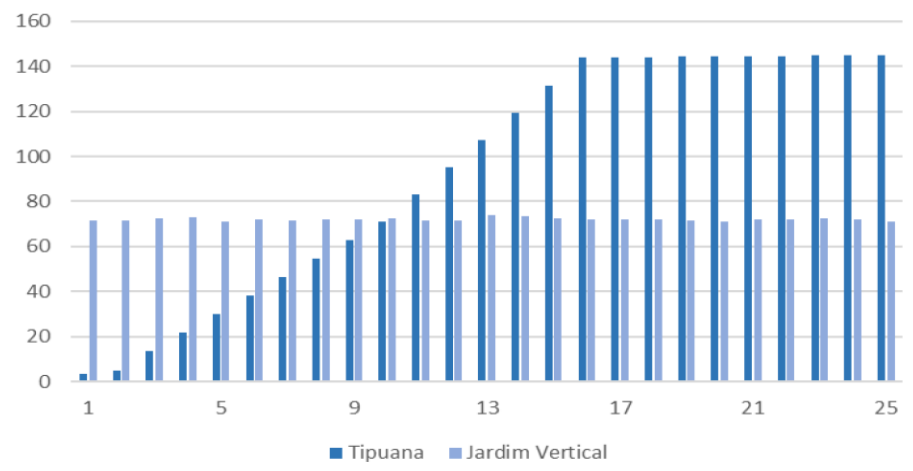

Fonte: Os autores, 2018

De acordo com Buckridge (2018) a diferença significativa dos valores das taxas de absorção de $\mathrm{CO}_{2}$ e de evapotranspiração é devido a quantidade de folhas presentes na copa de uma tipuana. Uma árvore que pode conter até 22 mil folhas de $140 \mathrm{~cm}^{2}$, correspondendo a uma área foliar de $308 \mathrm{~m}^{2}$. Uma parede viva composta por espécies de plantas com 4 camadas de folhas, por sua vez, tem uma área foliar de aproximadamente $150 \mathrm{~m}^{2}$, valor $50 \%$ inferior ao da área foliar da tipuana.

Segundo Brun et al. 2007, a arborização urbana desempenha importante papel na biodiversidade quanto ao fornecimento de abrigo, locais de nidificação e diversidade de alimentos para uma grande variedade da fauna silvestre, como observado nas figuras 1 e 2 . Para tanto, é necessário que o programa de arborização diversifique as espécies a serem plantadas para que constituem sistemas ecológicos urbanos.

Figura 1 - Gracilinanus microtarsus, marsupial arborícola

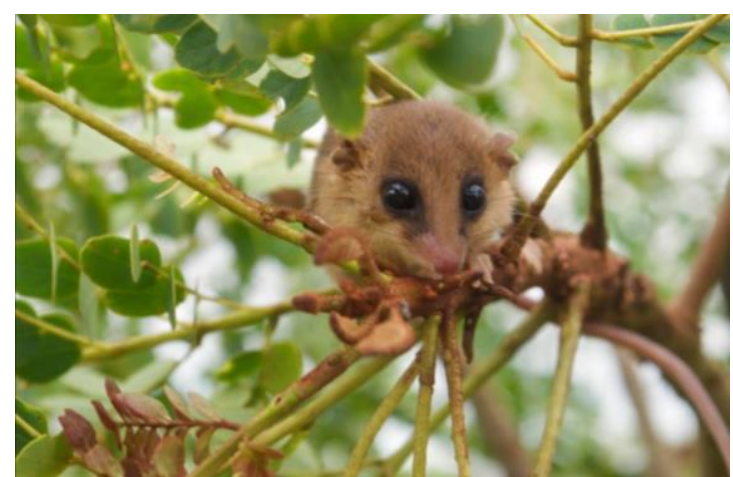

Fonte: Stefane Saruhashi, 2018 


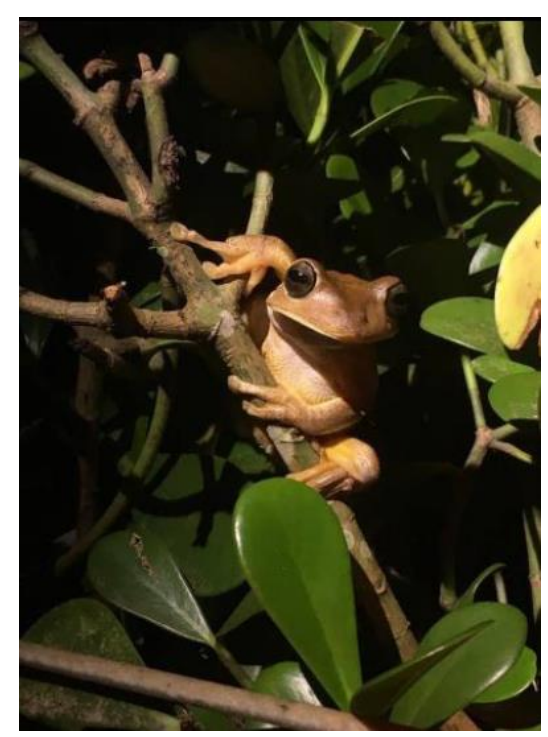

Fonte: Stefane Saruhashi, 2018

De acordo com Perini e Rosasco (2013), nos jardins verticais essa biodiversidade é questionável devido à altura em que estão fixados nas fachadas dos edifícios restringindo o acesso dos animais. Somado a isso, o sistema automático de irrigação pode levar ao acúmulo de água, tornando o ambiente propício ao desenvolvimento de vetores transmissores de doenças, como o mosquito Aedes aegypti, na figura 3. Além disso, é necessário critérios para a escolha das espécies vegetais, o uso de plantas exóticas no jardim vertical pode levar a dispersão delas em outros locais, assim, elas passam a competir com espécies nativas e geram ainda mais problemas associados à invasão de espécies exóticas.

Figura 3 - Aedes aegypti, inseto adaptado ao ambiente urbano, vetor de doenças como dengue, febre amarela, febre zica e chikungunya

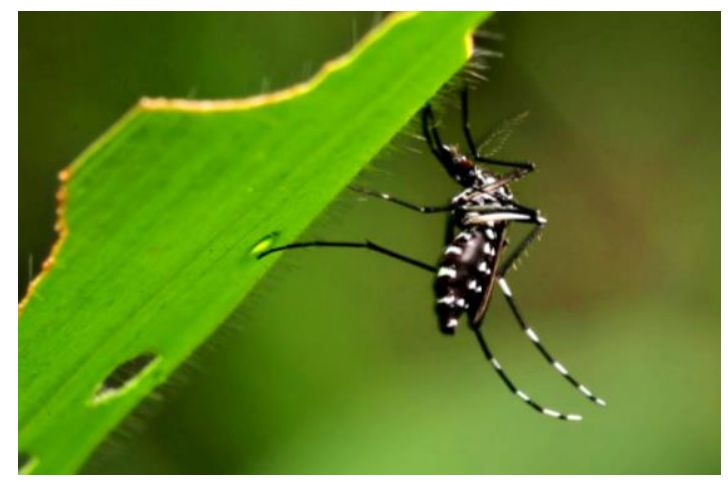

Fonte: Fernando Name (2016)

Com relação aos custos envolvidos no plantio de árvores para fins urbanísticos, nos padrões exigidos pela prefeitura, cada muda custa $R \$ 71,58$. Para primeiros meses é exigido critérios e técnicas adequadas para o seu desenvolvimento. Após a sua fixação no solo elas utilizarão a umidade e os nutrientes provenientes do solo e do ar para seu desenvolvimento, contendo reservas energéticas suficientes para sobreviver nos períodos de estiagem. Os valores de $R \$$ $84.410,00$ ao longo de 60 anos para uma tipuana, correspondem aos custos de manutenção e podas necessárias para evitar interferências na rede elétrica ou edificações (LEAL, 2007)

De acordo com Perini e Rosasco (2014), para uma parede viva de $36 \mathrm{~m}^{2}$ estima-se o valor de $\mathrm{R} \$ 48.072,10$ para sua instalação, manutenção anual de $R \$ 4.125,74$, manutenção a cada 50 anos de $\mathrm{R} \$ 107.727,40$ para troca de revestimento e recomposição das espécies. Um montante de $R \$ 403.343,90$. 


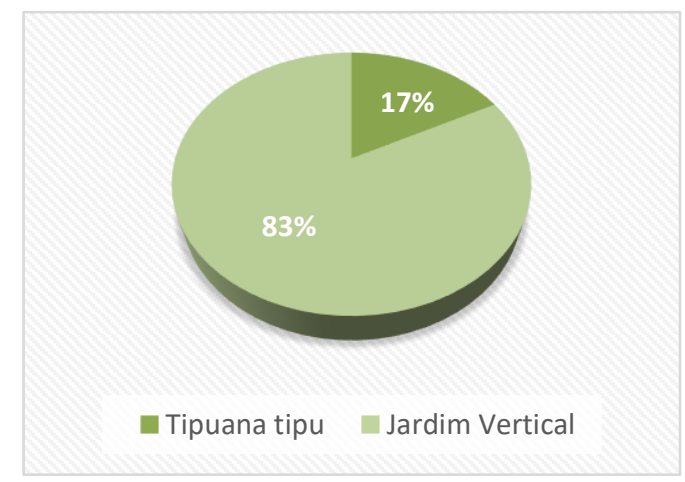

Fonte: Os autores, 2018

\section{CONCLUSÕES}

Os valores dos serviços ambientais estimados para uma tipuana superam os de uma parede viva, de mesma dimensão. Neste caso seria necessária uma área de $141,82 \mathrm{~m}^{2}$ de parede viva para suprir a quantidade de $\mathrm{CO}_{2}$ absorvida e uma área de $74 \mathrm{~m}^{2}$ de taxa de evapotranspiração para a tipuana. Porém, é necessário considerar que uma parede verde passará a fornecer seus serviços ambientais dentro de poucos meses, ao contrário do período de 10 anos necessário para uma tipuana começar a prestar estes mesmos serviços de maneira significativa.

Os custos de implantação e manutenção dos jardins verticais superam os custos de plantio e cuidados com as espécies arbóreas. Com os recursos investidos em um jardim vertical de 36 $\mathrm{m}^{2}$ seria possível plantar 5 árvores de grande porte, com maiores eficiências nos serviços ecossistêmicos como absorção de $\mathrm{CO}_{2}$, umidificação do ar e aumento da biodiversidade.

Portanto, os custos-benefícios quando comparados com espécies arbóreas, comprovam a insustentabilidade dos jardins verticais, não sendo recomendada sua utilização para Termos de Ajustamento de Conduta.

\section{REFERÊNCIAS}

BLANC, P. The Vertical Garden: A scientific and artistic approach. (2008). Disponível em: http://www.verticalgardenpatrickblanc.com/documents.

BRUN, F. G. K., LINK, D., BRUN, E. J. Emprego da Arborização na Manutenção da

Biodiversidade de Fauna em Áreas Urbanas. 2, 117-127 (2007).

BUCKRIDGE, M. Árvores Versus Paredes Verdes, disponível em

<https://msbuckeridge.wordpress.com> último cesso em mar de 2018

CAMERON, R W F, TAYLOR, J. E, EMMETT, MARTIN R. What's 'Cool' in the World of Green

Façades? How Plant Choice Influences the Cooling Proprieties of Green Walls. v.73, mar 2014. Disponível em < https://doi.org/10.1016/j.buildenv.2013.12.005> acesso em mar de 2018

HALLÉ, F.; OLDMAN, R.A.A.; TONLINSOM, P.B. Tropical trees and forest: an architectural analysis. Berlin: Springer Verlag, 1978

IRWIN, G. Hydroponic Living Walls - DIY - Really? disponível em

http://www.greenroofs.com/content/hydroponic_living_walls_diy_really, acessado mar 2018 
KLINE, J. R., MARTIN, J. R., JORDAN, C. F., KORANDA, J. J. Measurement of Transpiration in Tropical Trees with Tritiated Water. Vol 51, ISSN 1068-1073 nov 1970. Disponível em < https://doi.org/10.2307/1933635> acesso em mar. 2018.

KÖHLER, M. Green facades- A view back and some visions. Urban Ecosystems, Neubrandenburg, v.1 1, p. 423-436, 2008. Dispinível em <http://dx.doi.org/10.1007/s1 1252-0080063-x> acesso em mar de 2018

LEAL, L., BIONDI, D. e ROCHADELLI R. Custos das Árvores de Rua - Estudo De Caso: Cidade De Curitiba. Vol. 32, n.3 ISSN 0100-6762 (2008) disponível em <http://dx.doi.org/10.1590/S0100$6762200800030001>$ aceso em mar 2018.

MARTINS, C. e LUZ, S. Aproveitamento de Madeiras de Podas da Arborização Urbana: Áreas do Traçado Inicial de Maringá. In: IV SIMPÓSIO DE PÓS-GRADUAÇÃO EM ENGENHARIA URBANA / I ENCONTRO NACIONAL DE TECNOLOGIA URBANA de 06 a 08 de nov de 2013. Disponível em <http://www.simpgeu.poli.ufrj.br/index.php/simpgeu/simpgeu> acesso em mar de 2018

MANSO, M., \& CASTRO-GOMES, J. (2015). Green wall systems: A review of their characteristics. Renewable and Sustainable Energy Reviews, 41, 863871.doi:10.1016/j.rser.2014.07.203. acessado em jun 2019

PERINI, K., OTTELÉ, M., HAAS, E. M. Vertical greening systems, a process tree for green façades and living walls. V. 16 p. 265-277, jun de 2013. doi:10.1007/s11252-012-0262-3 disponível em < https://link.springer.com/article/10.1007/s1 1252-012-0262-3> acesso em mar de 2018.

PERINI, K. e ROSASCO, P. Cost - Benefit Analysis for Green Façades and Living Wall Systems. Build. Environ. V.70, p.110-121 Dez de 2013. Disponível em <

https://doi.org/10.1016/j.buildenv.2013.08.012> acessado em mar 2018

PULSELLI, R. M., SALADINI, F., NERI, E. e BASTIANONI, S. A comprehensive lifecycle evaluation of vertical greenery systems based on systemic indicators. V. 191, P; 1017-1024 (2014) DOI: 10.2495/SC 140862, disponível em <https://www.witpress.com/elibrary/wit-transactions-onecology-and-the-environment/191/29577>.acesso em mar 2018.

SÃO PAULO. Decreto n55.994, de 10 de março de 2015. Introduz alterações no artigo $4^{\circ}$ do Decreto $n^{\circ} 53.889$, de 08 de maio de 2013, que regulamenta o termo de compromisso ambiental- TCA. Diário Oficial, São Paulo, SP, acesso em mar. de 2015.

Geosampa, disponível em:

<http://geosampa.prefeitura.sp.gov.br/PaginasPublicas/_SBC.aspx> acesso em jun de 2017 